\title{
Trapezoid and Triquetrum Fracture: Report of a Rare Fracture Pattern
}

\author{
Murat Demiroglu ${ }^{*}$, Bulent Kilic ${ }^{2}$, Ayse Sencan ${ }^{3}$, Utku Gurun ${ }^{4}$, Serkan Aykut ${ }^{5}$, \\ Kahraman Ozturk ${ }^{5}$ \\ ${ }^{1}$ Department of Orthopaedics and Traumatology, Medeniyet University Goztepe EAH, Istanbul, Turkey \\ ${ }^{2}$ Gelisim University Health Sciences, Istanbul, Turkey \\ ${ }^{3}$ Bagcilar EAH, Department of Hand Surgery, Istanbul, Turkey \\ ${ }^{4}$ Bagcilar EAH, Department of Orthopaedics and Traumatology, Istanbul, Turkey \\ ${ }^{5}$ Baltalimani EAH, Hand Surgery Department, Istanbul,Turkey \\ Email: *drmuratdemiroglu@gmail.com,drbulentk@hotmail.com, aysencan35@gmail.com, \\ utkugurun@yahoo.com, aykutserkan@yahoo.com,kahraman_ozturk@hotmail.com
}

Received 21 January 2016; accepted 21 February 2016; published 26 February 2016

Copyright (C) 2016 by authors and Scientific Research Publishing Inc.

This work is licensed under the Creative Commons Attribution International License (CC BY).

http://creativecommons.org/licenses/by/4.0/

(c) (i) Open Access

\begin{abstract}
Trapezoid bone fracture is the least common fracture owing to the fact that it is strictly bounded to scaphoid, capitate and the base of the second metacarpal. Isolated fractures are rarely seen and usually related to the high energy trauma. It is conservatively treated without dislocation. Triquetrum fractures are the second least common fractures among carpal bones. The body fractures are usually caused by a fall onto an open flexed hand. Non-displaced fractures can be treated conservatively. Our aim is to remind those rare fractures of the carpal bones that accompany the wrist trauma, which can require additional radiological studies.
\end{abstract}

\section{Keywords}

Trapezoid, Triquetrum, Fracture, Wrist

\section{Introduction}

Trapezoid bone fracture is the least common fracture owing to the fact that it is strictly bounded to scaphoid, capitate and the base of the second metacarpal. Triquetrum fractures are the second least common fractures among carpal bones [1]-[3]. The trapezoid bone is located in the 2nd metacarpal, trapezium, capitate and scaphoid bones and is firmly connected to them, without any possibility of movement [4]. Isolated fractured are rarely seen and the diagnosis may be missing. In the presence of doubt computerized tomography examination should be performed.

${ }^{*}$ Corresponding author.

How to cite this paper: Demiroglu, M., Kilic, B., Sencan, A., Gurun, U., Aykut, S. and Ozturk, K. (2016) Trapezoid and Triquetrum Fracture: Report of a Rare Fracture Pattern. Open Journal of Orthopedics, 6, 29-31.

http://dx.doi.org/10.4236/ojo.2016.62005 


\section{Presentation of the Case}

The patient was a 24-year-old male who was presented to our clinic 3 days after his motorcycle accident. He went a hospital after his injury and three-view radiograph of his wrist did not show a fracture. Therefore, immobilization by splint was not recommended to the patient.

A computerized tomography (CT) scan of the right and left hand was obtained.

His prominent complaints were pain in the second metacarpal base and moderate swelling.

CT scan of the right and left wrists demonstrated a non-displaced trapezoid and non-displaced triquetrum fractures, respectively (Figure 1 and Figure 2).

We have applied a short arm cast for a period of 5 weeks with wrist slightly extension and additionally 1 week splint bilaterally.

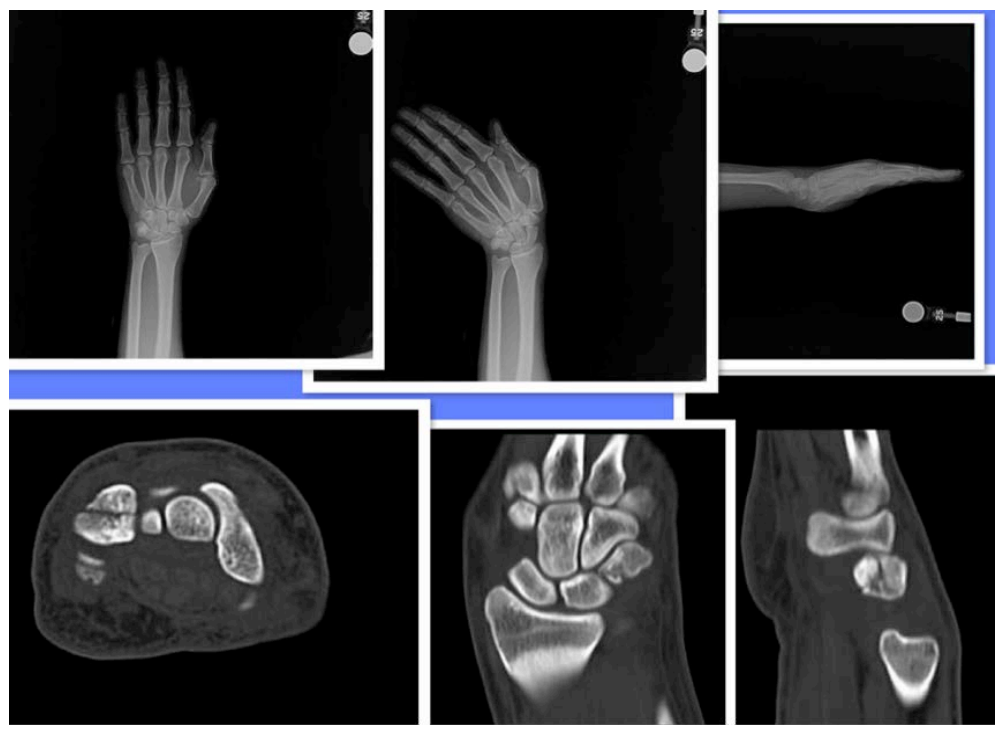

Figure 1. Left hand AP; Left hand scaphoid view; Left hand lateral; Left hand axial CT (triquetrum fracture is observed); Left hand coronal CT; Left hand sagittal CT.
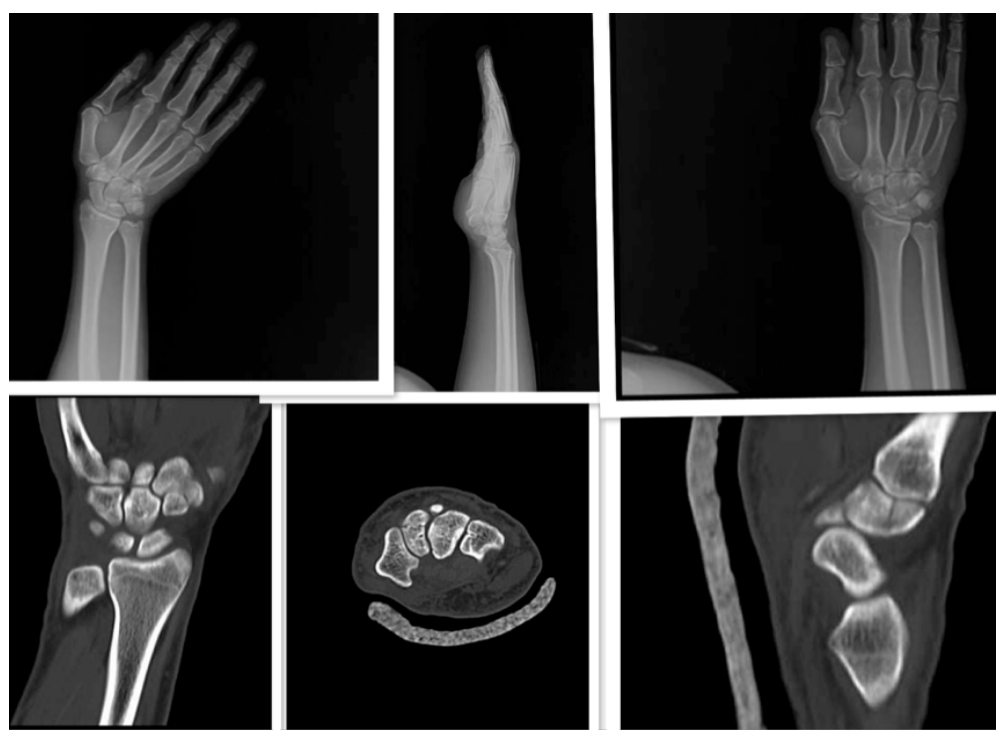

Figure 2. Right hand scaphoid view; Right hand lateral; Right hand AP; Right hand coronal CT; Right hand axial CT; Right hand sagittal CT (trapezoid fracture is observed). 
The complaints about the pain and swelling were completely resolved after 6 weeks; however, right wrist did not recover to the range of motion. The patient has refused physical therapy.

After 3 months, both right and left wrists of the patient were in 80 - 85 degree of flexion, however, wrist extensions had 45 degrees in right whereas 60 - 65 degrees in left wrists.

During final follow-up visit of the patient, all functions were recovered completely with the exception of wrist extension on the right side.

\section{Discussion}

The trapezoid fractures are rarely seen among carpal fractures with $0.4 \%$ frequency [1]-[3] [5]. Axial loading is accused through the second metacarpal base. The swelling and persisting pain above this region must remind us of non-displaced fractures.

Trapezoid shape is like a keystone and the trapezoid bone; dorsal side, according palmar surface is twice as large.

Injury to trapezoid can occur with axial force. As experienced in our case, it appears that axial force was applied to the second metacarpal base.

If fracture-subluxation exists in a patient even it is a rare situation, closed reduction and percutanos pinning should attempt. But if it is not possible, open reduction should be carried out.

Our patient was injured as a result of a motorcycle accident. In another study, we reported a trapezoid fracture and his case etiology was a drink-driven crush [4].

In our case, diagnosis was late due to lack of CT scan during the first visit.

We applied the immobilization for only 6 weeks; however, the immobilization period may not be sufficient, resulting lack of extension.

Our patient refused physical therapy but immobilizations time can be a more predictable factor. Sadowski and Montilla [5] had a similar case with us and succeeded with full functional recovery by applying immobilization for 8 weeks.

Despite the absence of evidence of a fracture in plain wrist x-rays, CT scanning should be performed in patients with ongoing pain in their first follow-up visit.

If persistent pain exists in the second metacarpal base, we must be alert for trapezoid fracture. It is easily misdiagnosed by checking only plain radiograph, CT scan should be performed for correct diagnosis.

We do not haveanyfinancialsponsor with the organization that sponsored the research.

\section{Consent}

Informed consent was obtained from the patient to report this case.

\section{Conflicts of Interest}

None.

\section{Authors' Disclosure Statement}

The authors report no actual or potential conflict of interest in relation to this article.

\section{References}

[1] Blomquist, G.A., Hunt III, T.R. and Lopez-Ben, R.R. (2013) Isolated Fractures of the Trapezoid as a Sports Injury. Skeletal Radiology, 42, 735-739. http://dx.doi.org/10.1007/s00256-013-1581-z

[2] Kain, N. and Heras-Palou, C. (2012) Trapezoid Fractures: Report of 11 Cases. Journal of Hand Surgery, 37, 11591162. http://dx.doi.org/10.1016/j.jhsa.2012.02.046

[3] Kam, M.L., Sreedharan, S., Teoh, L.C. and Chew, W.Y. (2011) Severe Isolated Trapezoid Fracture: A Case Report. Hand Surgery, 16, 185-187. http://dx.doi.org/10.1142/S0218810411005321

[4] Watanabe, H., Hamada, Y. and Yamamato, Y. (1999) A Case of Old Trapezoid Fracture. Archive of Orthopaedic and Trauma Surgery, 119, 356-357. http://dx.doi.org/10.1007/s004020050427

[5] Sadowski, M.R. and Montilla, D.R. (2008) Rare Isolated Trapezoid Fracture: A Case Report. Hand, 3, 372-374. http://dx.doi.org/10.1007/s11552-008-9100-8 